\title{
O conhecimento de si mesmo na narrativa autobiográfica de Girolamo Cardano
}

\author{
Knowledge of himself in the autobiographical narrative of Girolamo Cardano \\ El conocimiento de sí mismo en la narrativa autobiográfica de Girolamo Cardano
}

Marina Massimi ${ }^{*}$

\begin{abstract}
Resumo
$\mathrm{O}$ artigo apresenta uma fonte histórica muito significativa no âmbito do gênero autobiográfico: as obras Liber de propria vita e Liber de libris propriis, do médico, matemático, astrólogo e pensador italiano Girolamo Cardano (1501-1576). O objetivo é analisar nelas o conhecimento de si mesmo elaborado pelo autor. A análise foi conduzida pelo método histórico conceitual, evidenciando-se os principais tópicos discutidos e suas significações à luz do universo sociocultural e histórico. Os resultados apontam para a complexidade do conhecimento construído pelo autor, que compreende a descrição de suas características físicas e psicológicas (incluindo os sonhos), o encadeamento dos fatos principais de sua história biográfica, a descrição de sua complexa personalidade construída com base em uma interpretação de si mesmo, à luz da identificação de suas motivações fundamentais.
\end{abstract}

Palavras-chave: Girolamo Cardano. Narrativa autobiográfica. História dos saberes psicológicos.

\begin{abstract}
The article discusses a very significant historical source in the autobiographical genre: the works of Girolamo Cardano (1501-1576), mathematician, astrologer and Italian thinker: Liber de propria vita and Liber de libris propriis physician. The aim is to analyze them through selfknowledge drawn on by the author. The analysis was conducted via the historical conceptual method: showing the main topics discussed and their meanings in the light of its historical and socio-cultural universe. The results point to the complexity of knowledge built on by the author and discussion of relevant aspects: the description of his physical and psychological characteristics (including dreams); the chain of events leading to his biographical history; the description of his complex
\end{abstract}

Texto recebido em fevereiro 2013 e aprovado para publicação em novembro de 2013.

Doutora em Psicologia Experimental pela Universidade de São Paulo, mestra em Psicologia Experimental pela USP, graduada em Psicologia pela Università degli Studi di Padova.E-mail: mmassimi3@yahoo.com. 
personality constructed from an interpretation of himself in the light of identifying their fundamental motivations.

Keywords: Girolamo Cardano. Autobiographical narrative. History of psychological knowledge.

\section{Resumen}

El artículo presenta una fuente histórica muy significativa del género autobiográfico: Liber de propria vita y Liber de libris propriis, del médico, matemático, astrólogo y pensador italiano Girolamo Cardano (15011576. El objetivo es analizar en ellas el conocimiento de sí mismo elaborado por el autor. El análisis se realizó por el método histórico conceptual, destacando los principales temas tratados y su significado a la luz del universo sociocultural e histórico. Los resultados ponen de manifiesto la complejidad del conocimiento construido por el autor, que comprende la descripción de sus características físicas y psicológicas (incluyendo los sueños), el encadenamiento de los principales acontecimientos de su historia biográfica, la descripción de su compleja personalidad, construida desde una interpretación de sí mismo a la luz de la identificación de sus motivaciones fundamentales.

Palabras clave: Gerolamo Cardano. Narrativa autobiográfica. Historia de los saberes psicológicos.

\section{Introdução}

historiador da psicologia Robert Watson (1998) afirma que, apesar de hoje o estudo da personalidade ser objeto da Psicologia científica, estudiosos de outras áreas também "reclamam para si a função de estudar a personalidade - o psiquiatra e o filósofo" (p. 389). Isso exige que outros âmbitos, como a história da Medicina e da Filosofia, sejam estudados, onde "os estudos sobre as pessoas eram feitos no contexto de consideraçôes filosóficas, médicas, científicas, religiosas, políticas ou literárias", em campos, muitas vezes, "totalmente estranhos à psicologia e ao estudo da personalidade no sentido contemporâneo". Ainda segundo o historiador, "a indagação de como a pessoa era considerada ao longo do tempo histórico é pertinente" (Watson, 1998), pois é inegável o fato de que:

Filósofos, médicos, teólogos e escritores têm feito observações introspectivas que não perderam sua importância diante do estudo da personalidade e às vezes ultrapassam o resultado produzido pela aplicação dos métodos científicos a este objeto (p. 390). 
Entre esses documentos, as fontes autobiográficas são de notável riqueza, como já assinalamos em outro artigo (Massimi, 2011). O objeto deste artigo é uma autobiografia elaborada no século XVI, que evidencia a importância que o conhecimento de si mesmo assume para os intelectuais ocidentais no alvorecer da Modernidade.

Com efeito, a autobiografia "De própria vita" (1576) e a autobibliografia "Liber de libris propriis" (1562) de Gerolamo Cardano, médico, matemático e filósofo milanês, constituem-se em densos relatos acerca da compreensão de si mesmo, escritos por um autor expressivo dos inícios da Idade Moderna. As pesquisas contemporâneas acerca do autor têm enfatizado que os aspectos tidos como extravagantes de sua personalidade podem ser plenamente entendidos como expressivos das tensões e aspirações antropológicas de sua época (Canziani, 2009; Cardano, 2002).

A autobibliografia, iniciada em 1543 e reelaborada em várias versões em 1557 e em 1562, comparece também no $45^{\circ}$ capítulo de sua autobiografia, no qual, de modo original e único, relata, em pormenores, todos os livros por ele escritos, inclusive justificando as relações da escrita de cada um desses livros com seu caráter, história de vida, motivações, meio cultural de seu tempo e até sonhos (Cardano, 2002). Na versão de 1562 da autobibliografia, Cardano (2002) elabora também um relato autobiográfico. Desse modo, nossa análise verterá sobre esses dois textos, de certo modo, entre si complementares.

\section{As motivações da escrita autobiográfica e autobibliográfica}

A autobiografia (1576), organizada em 54 capítulos, foi escrita já no fim da vida e, conforme afirmado no preâmbulo (Cardano, 1932, p. 45), tem a função de defender-se da calúnia, com base no exemplo do filósofo estoico Marco Aurélio (121-181 d.C.), imperador romano, filósofo e escritor de meditações de teor autobiográfico (2001). Cardano relata que o método da escrita foi coletar os eventos testemunhados também pelos seus discípulos e ordená-los no texto. Insere sua narrativa numa tradição trilhada inclusive por autoridades da ciência médica. Relata que possivelmente o próprio Galeno tentou escrever uma autobiografia, espalhando notas pessoais em seus escritos médicos, mas que, infelizmente, seus intérpretes e comentadores "por preguiça, descuidaram de extrair e ordenar essas notícias, presentes em suas obras" (Cardano, 1932, p. 45). Aos leitores, a obra é proposta pelo seu autor nestes termos: "Eis aqui, caro leitor, minha biografia, apresentada assim sem mentiras ou soberbia; história nua de uma vida tumultuada que nada tem a ver com grandes gestas". E ainda confessa que, ao escrevê-la, não tinha 
a pretensão de fazer algo novo ou uma invenção (Cardano, 1932, p. 46, tradução nossa).

Quanto ao "Liber de libris propriis" (1562), Cardano (2002) afirma que a obra nasceu pela exigência de esboçar um retrato de tudo o que ele mesmo escrevera, não apenas para ajudar sua memória e sinalizar os livros ainda a terminar ou corrigir como também: "para mostrar por quais razões, em que momento e em que ordem eu compus tais obras; e para dar testemunho da ajuda recebida por Deus em cada caso" (Cardano, 2002, p. 94, tradução nossa).

No prólogo, o autor declara não haver nada tão "espinhoso e difícil como escrever algo sobre si mesmo e colocar em forma de documento as ações e empresas de sua própria vida" (Cardano, 2002, p. 57, tradução nossa). Com efeito, "se você louva ou critica sua própria pessoa ou suas coisas, se exagera ou diminui algo nesta descrição", a exposição pública da própria pessoa poderá acarretar prejuízos para si e para outros. Devido a esse motivo, segundo o escritor, poucos se atreveram a empreender essa tarefa, entre os quais cita César (100-44 a.C.), Cícero (106-43 a.C)., Marco Aurélio (121-181 d.C.), Galeno (129-199 d.C.), Jerônimo (347-420), Agostinho (354-430), Erasmo (1466-1536). Todavia a originalidade de Cardano, segundo ele próprio, decorreria do fato de que não elaborou apenas uma simples listagem das suas obras, e sim uma narrativa das motivações, gêneses, circunstâncias biográficas em que elas foram realizadas.

Cardano afirma reconhecer coisa "conveniente e necessária" descrever sua própria produção, apontando a "razão da pública utilidade" que o inspirou, tendo também o objetivo de "avaliar e completar o que falta, como também tirar algum prazer na consideração de meus passados trabalhos, nestes tempos atuais tão penosos, quando já a minha vida está desmoronando" (Cardano, 2002, p. 58, tradução nossa). E aqui já se revela a função muito importante que o autor atribui à escrita, função múltipla como veremos, incluindo a afirmação e o conhecimento da própria personalidade, como também a função consolatória e, sobretudo, a função de garantir ao seu autor a imortalidade.

Num certo ponto do livro, Cardano questiona-se a si mesmo: "Que proveito você tirou de seus livros? Pois caso não serviram a ti mesmo, como poderia garantir aos demais de sua utilidade e qual esperança terás de tê-la?" (Cardano, 2002, p. 106, tradução nossa). E responde que o saber de uma pessoa comunicado aos outros tem uma utilidade social que transcende o uso para si próprio que essa mesma pessoa possa fazer desse saber; ademais, afirma de si que, de qualquer forma, apesar dos eventos dramáticos de sua 
vida, "salvei-me a mim mesmo, com a ajuda de Deus e o conhecimento dessas ciências” (Cardano, 2002, p. 106, tradução nossa).

$\mathrm{Na}$ autobiografia, Cardano relata também seus hábitos, vícios e erros, evidenciando a originalidade de sua abordagem autobiográfica caracterizada pela sinceridade. Nisso ele assinala um novo sentido de autobiografia: não mais uma narrativa exemplar, modelar, e sim uma narrativa centrada na vivência subjetiva (Massimi, 2011), conforme, depois dele, outros autores, como Montaigne e Rousseau, farão. Ressaltando sua própria originalidade, escreve: "Eu prefiro dizer toda a verdade, mesmo não ignorando que quem peca contra os costumes não é justificável” (Cardano, 1932, p. 125).

O conhecimento de si mesmo nos textos de Cardano se articula desde a descrição das circunstâncias externas determinantes de sua vida, para depois ilustrar os fatos históricos e os traços psicossomáticos de sua personalidade. Em seguida, ele adentra, na busca do motivo dominante, o seu percurso existencial consciente, a saber, o anseio pela imortalidade; e, à luz desse motivo, relê suas dimensões e posicionamentos pessoais e fornece, fundamentado nisso, uma interpretação unitária e coerente de si mesmo, e uma visão de sua existência positivamente orientada, apesar de atravessada por circunstâncias adversas.

\section{Influência de relações e fatos de vida familiar na percepção de si mesmo}

O primeiro capítulo da autobiografia é dedicado a descrever a família e o lugar de nascimento: a aldeia Cardano del Campo, de onde deriva o sobrenome do autor, situada a cerca de 43 quilômetros da cidade de Milão, perto da cidade de Pavia. A história familiar é relatada a partir do patriarca Milone Cardano, de quem há uma notícia datada do ano de 1189. Já no "Liber de libris propriis" (1562), Cardano (2002) relata alguns pormenores interessantes quanto à configuração das relações familiares no tempo de sua gestação e nascimento: o fato de ter nascido na aldeia perto de Pavia e não em Milão, cidade de residência dos pais, dependeu da vontade dos genitores de ocultar ao público a notícia do nascimento do filho, por ser este ilegítimo. $\mathrm{O}$ pai era um rico advogado, e a mãe, pobre e viúva.

No segundo capítulo do "Liber de propria vita" (1576), Cardano (1932) ilustra as circunstâncias de seu nascimento, no dia 24 de setembro de 1500 . Conforme seus conhecimentos astrológicos, Cardano descreve as figuras do horóscopo com base no mapa astral da hora do nascimento, que explicará algumas características de sua vida: o fato de que o planeta "Júpiter estava em sua fase ascendente" e que "Venus dominava totalmente a constelação" acarreta consequências no campo da sexualidade: "Ao ponto que, entre 21 
e 31 anos de idade, não consegui manter relações sexuais com mulheres" (Cardano, 1932, p. 53). Ao seu mapa astral o autor atribui também algumas deficiências e qualidades de sua pessoa: ser gago e ter "uma predisposição para a divinação" (Cardano, 1932, p. 53). Além disso, à ocorrência de que, "naquela hora, o sol já se tinha posto" atribui sua "escassa astúcia e seu ânimo pouco liberal e disposto a julgamento precipitados e contraditórios" (Cardano, 1932, p. 54, tradução nossa). Por fim, Cardano deriva de causas astrológicas sua complexão: "Eu fiquei assim como eu sou, desprovido de forças físicas, pouco disposto às amizades e a gerenciar patrimônio, rico apenas de inimigos", "carente em sabedoria humana, fraco quanto à memória, dotado de capacidade de premonição" (Cardano, 1932, p. 54).

No terceiro capítulo, Cardano descreve as características de seus pais: o pai era também gago, deleitava-se nos estudos, tinha poucos amigos; a mãe era "pronta para a ira, dispunha de aguda memória e engenho, de pequena estatura" (Cardano, 1932, p. 58, tradução nossa). Afirma que "ambos os pais facilmente deixavam-se levar pela ira e eram inconstantes em seus cuidados e afeto para com o filho" (Cardano, 1932, p. 58).

Noutro capítulo, relata as desgraças sofridas pela sorte desventurada dos filhos: a esposa falece ainda jovem, sendo que um dos filhos é condenado à morte por ter envenenado a mulher e é decapitado. Devido ao ocorrido, Cardano tem de deixar o ensino em Pavia e sofre a marginalização social: "Eu andava pelas ruas da cidade, malquisto por todos e desprezado nas conversas, mal tolerado pelos amigos, os quais eu também buscava evitar" (Cardano, 1932, p. 186). Além disso, Cardano ainda deve suportar os maus-tratos do filho menor. Nessa situação de extremo sofrimento, Cardano confessa buscar na escrita consolação, assim como fez Cícero.

\section{Retrato de si mesmo pela escrita}

No capítulo quarto de "Liber de vita própria", Cardano (1932) traça um breve resumo de sua vida até o outubro de 1575, data em que escreve sua autobiografia. O capítulo quinto é dedicado à descrição de seu aspecto físico e o sexto à descrição de seu estado de saúde e relato de suas inúmeras patologias e de sua complexa personalidade, caracterizada por hipocondria e acentuada tendência masoquista: "Costumava buscar motivos de dor mesmo quando não havia, hábito este que espantava os outros"; "Às vezes, era eu mesmo que ia ao encontro das causas das moléstias". Com efeito, "Eu pensava que o prazer consiste na cura de uma aflição precedente; e que, se a dor for buscada voluntariamente, seria também fácil de sedá-la” (Cardano, 1932, p. 
89, tradução nossa). Desse modo, "experimentei que nunca me poderia faltar completamente dor" para evitar a emergência de "uma sensação sobremaneira molesta, aguda e sofrida" (Cardano, 1932, p. 90). Cardano confessa ter provocado ao seu corpo "dores até chorar por mordidas de lábios, entortandome os dedos, beliscões na pele e no músculo do braço esquerdo". Além disso, narra ter sido "acometido por paixóes amorosas heroicas que me levaram a cogitar suicídio" (Cardano, 1932, p. 90, tradução nossa).

Outros capítulos são dedicados ao relato dos exercícios corporais que costumava realizar, aos hábitos alimentares, ao modo de viver, aos lugares em que morou, às condições econômicas, ao casamento e aos filhos. No décimo capítulo, relata, em pormenores, sua rotina durante o tempo de docência em Milão e Pavia, hábitos bem equilibrados, de certo modo contrastantes com o desequilíbrio de suas vivências interiores e comportamentos. Ao descrever seus estados de ânimo, comenta que "Era como um touro enfurecido que, quanto mais tendo olhos fechados é levado pelo ímpeto, tanto mais se choca e é abatido" (Cardano, 1932, p. 111). E ao dedicar o $11^{\circ}$ capítulo à prudência, evidencia que esta é a virtude que lhe faltou em vida.

No $13^{\circ}$ capítulo, elenca suas normas de vida:

a) acolher os eventos como admoestação divina ("reconhecendo-o dentro da ordem universal", p. 168);

b) implorar sempre o espírito divino; tirar vantagens das desgraças;

c) não perder tempo; venerar os idosos e buscar sua companhia;

d) observar e acreditar que, na natureza, nada acontece ao acaso;

e) preferir sempre o certo ao incerto;

f) nunca persistir contra a razão;

g) entregar-se à experiência também no exercício da Medicina.

Em outras partes da autobiografia, Cardano relata seu empenho nas disputas e atividades de ensino na universidade das cidades de Bolonha, Pavia, Milão, na Itália, como também na França e Alemanha. Evidencia seus dotes dialéticos e seu engenho, características muito valorizadas pela cultura de sua época (Battistini, 2000): "Não havia mais ninguém que quisesse me contradizer nas disputas" (Cardano, 1932, p. 120).

Acerca de seu temperamento, afirma ser, "por natureza, iracundo, ingênuo, dedicado aos prazeres de Vênus" (Cardano, 1932, p. 126) e que desses elementos de personalidade brotam crueldade, agressividade, imprudência, desejo de vingança. Todavia declara que, juntamente com esses aspectos, 
tem também características positivas, tais como o amor à verdade, a gratidão pelos benfeitores, o amor pela justiça, o amor pela família, o desprezo pelo dinheiro e pela mediocridade, o cultivo da glória além do túmulo. Apesar de ser sobremaneira vingativo, diz que evita deliberadamente as ocasiões de vingança, seja por respeito à Divindade, seja pela consciência da vaidade de todas as coisas, inserindo assim, em seus traços autobiográficos, topoi da cultura de seu tempo: a religiosidade e o desengano (Massimi, 2005). Ao prosseguir o retrato pormenorizado de suas características psicossomáticas, declara: "Sou tímido, tenho coração frio e cérebro quente, dedico-me constantemente à meditação e fico fantasiando com muitas coisas, também irrealizáveis. Sou também capaz de aplicar minha mente simultaneamente em dois raciocínios" (Cardano, 1932, p. 127). Confessa também ter bem aprendido o hábito da simulação, comum na época (Míssio, 2005): "Acostumei meu rosto para moldar a expressão sempre contrária ao que vivencio interiormente" (Cardano, 1932, p. 127).

Outras confissões de Cardano são: o descuido de sua aparência física; a falta de piedade e o excesso no uso das palavras, sobretudo quando levado pela ira; a paciência na tolerância das dores (Cardano, 1932, p. 128); e o enorme prazer em dizer tudo quanto possa desagradar os ouvintes (Cardano, 1932, p. 129). Declara viver o mais solitariamente possível, sofrer falta de amigos, sobretudo confiáveis, (Cardano, 1932, p. 130); ser apressado no julgar; e descomedido jogador de xadrez (Cardano, 1932, p. 131).

\section{$\mathrm{O}$ anseio pela imortalidade como motivo condutor da autoconsciência de Cardano}

O capítulo nono assume função central na autobiografia, por ser dedicado ao motivo principal que levou o autor à escrita autobiográfica: "o pensamento de eternizar meu nome". Confessa:

Tão cedo tive a ideia e o desejo de imortalizar meu nome, quão tardio foi o êxito logrado. [...] Com efeito, eu compreendera que a vida deve ser dupla: a existência material, que é comum também aos animais e as plantas; e a existência própria dos homens desejosos de glórias e de empreender grandes ações (Cardano, 1932, p. 103, tradução nossa).

Cardano (1932) avalia que, quanto ao primeiro gênero de vida, ligado à matéria, pela sua deficiente natureza, não teria esperança de se sobressair e que, quanto ao segundo gênero, ou seja, à glória e ao sucesso, não disporia de recursos econômicos e de excelência de dotes pessoais para tanto. Nesse quadro que não parecia muito promissor, Cardano relata a ocorrência de 
alguns fatos extraordinários que mudaram o trajeto de uma história de vida que se presumiria medíocre. Em primeiro lugar, um sonho (como veremos, os sonhos premonitórios marcam a biografia do autor):

Mas eis que, após alguns anos, aconteceu-me de sonhar, e aquele sonho me fez conceber a esperança do segundo gênero de vida. Eu não saberia dizer como, mas o fato é que, após aquele sonho, sentira-me facilitado como que milagrosamente para a compreensão do idioma latim (Cardano, 1932, p. 103-104, tradução nossa).

Em "Liber de libris propriis" (1562), Cardano (2002) relata em pormenores o referido sonho: sonhou estar numa alvorada, junto com uma multidão imensa de pessoas que corriam aos pés de uma montanha. Ao perguntar a um homem para onde se dirigia aquela multidão, respondeu-lhe que para a morte. Então ele tentou, de qualquer jeito, subir a montanha, para evitar cair "num profundo vale negro e abismo tão sinistro que só ao lembrá-lo me inquieta" (Cardano, 2002, p. 76, tradução nossa). Na subida, deu com uma cabana e, na porta, um menino. Este o tomou pela mão e o levou para dentro. Cardano conta que interpreta esse sonho da seguinte forma: ao seguir o impulso natural, todos os seres humanos andam em direção à morte e terminam assim sua vida terrena como também inviabilizam sua própria fama. Cardano, pelo contrário, fora "aconselhado pelo Gênio que subisse a montanha da excelência" (Cardano, 2002, p. 76). O abismo era o evento da morte do próprio filho, do qual ele conseguiu superar pela dedicação ao saber; a cabana simbolizava a tranquilidade de espírito, e o jovem era o seu discípulo, Ercole Visconti.

No capítulo décimo do "Liber de propria vita" (1576), Cardano (1932) relata que, com base nessas premoniçôes, a partir da infância e juventude, buscou "conformar meu gênero de vida ao objetivo de eternizar meu nome, não tanto como eu gostaria de fazer, mas do jeito que foi possível" (Cardano, 1932, p. 109, tradução nossa). Mesmo quando não consegue "manter-me coerente e constante no meio de tantos perigos, carências e dificuldades", afirma: "Olhei para o escopo que era de ganhar para mim, em algum modo, um nome durável”. Portanto,

não busquei riquezas, nem comodidades, nem honras, nem cargos públicos, nem poder; e sim a pura adesão àquele anseio que devia superar os obstáculos todos: as desgraças e acasos, os inimigos e os tempos adversos, minha ignorância e incapacidade (Cardano, 1932, p. 109, tradução nossa). 
Cardano reconhece que, paradoxalmente, um dos maiores empecilhos que enfrenta em realizar seu objetivo de vida é o conhecimento de seu mapa astrológico e de suas condições psicossomáticas que o levam à falsa crença no determinismo das circunstâncias da existência humana:

Os conhecimentos astrológicos que eu então tinha assim como as minhas características somáticas e a opinião dos meus familiares coincidiam em persuadir-me acerca do fato de que eu não passaria do quadragésimo quinto ano de vida. E, portanto, apesar de eu decidir viver retamente, deixava-me desviar pelas circunstâncias e pelos convites das paixões. Desse modo, por causa de uma crença vã, descuidei do essencial e às escolhas errôneas também se sucederam ações pecaminosas. Aconteceu, porém, que, quando eu acreditava estar morrendo, comecei a viver verdadeiramente, tendo a idade de quarenta e três anos; e então me entreguei ao gozo descompromissado, induzido também pela idade, pelo temperamento, pelo descuido no que diz respeito aos deveres e também pelos acasos da vida (Cardano, 1932, p. 110, tradução nossa).

Cardano aprofunda o sentido de seu "desejo de imortalidade" (Cardano, 1932, p. 104) como elemento motivador da escrita autobiográfica, bem como os questionamentos enfrentados pelo escritor em sua autoconsciência:

$\mathrm{Na}$ verdade, o raciocínio me detinha diante desse desejo de imortalidade, com a consideração de que nada seria mais vão do que essa esperança, na medida em que esta não fosse contida apenas no limite de um mero desejo. E conversava comigo mesmo: saberás tu escrever coisas dignas de serem lidas ou encontrarás assuntos tão novos e, apesar disso, por ti tão conhecidos, de modo a atrair a curiosidade dos leitores? Terás o estilo e a elegância da argumentação adequados para atrair e prender o leitor? Ou não haverá de acontecer que, após a asa devastadora do tempo e após o aumento cotidiano dos escritos, estes possam cair no desprezo ainda antes do que cair no esquecimento? Terão estes escritos a duração de muitos anos, e quantos? Cem, mil, dez mil? Tu podes citar o exemplo de apenas um livro entre milhares que durou tanto tempo assim? E se a alma for imortal, que necessidade haveria de nomes e palavras? Mas, se pelo contrário, a alma perecer, a que vale a sobrevivência de nomes e palavras? Quando uma geração é destinada ao fim, tudo se acaba com ela, assim como acontece no caso das lebres e dos coelhos? (Cardano, 1932, p. 104)

Finalmente, Cardano afirma que, apesar de tais questionamentos acerca dos limites do anseio pela imortalidade que o move em elaborar a narrativa autobiográfica, o desejo de escrever se sobressai. Ele mesmo se maravilha por isso: "É admirável que, apesar de todos aqueles raciocínios e discursos, ainda agora eu continue ardendo pelo desejo da imortalidade, mesmo sabendo se tratar de um amor vão" (Cardano, 1932, p. 106, tradução nossa). 
Esse motivo condutor identificado na autoconsciência da pessoa como o fator de unidade de suas vivências é tematizado por vários autores no âmbito das Ciências Humanas (como Adler, Frankl, Stein): entre eles, Giussani (como citado em Mahfoud, 2012) define o conceito de "experiência elementar" como aquele

Ímpeto original que está na base de todo gesto ou posicionamento humano, pelo qual a pessoa pode reconhecer suas exigências fundamentais (de felicidade, de justiça, por exemplo) e também reconhecer evidências fundamentais (como a da própria existência e a de uma realidade que a transcende) (p. 34).

Ainda segundo Giussani (como citado em Mahfoud, 2012),

Assim identificada, a própria experiência fornece critérios de avaliação que permitem chegar a juízos pessoais a respeito da correspondência entre tudo o que o sujeito encontra no mundo e na história, e os anseios que constituem a própria pessoa (p. 34).

Cardano identifica, com muita clareza, a "experiência elementar" em suas vivências, como um "desejo de ser": confessa que não nutre anseios de glórias e honras e de "amar que os homens saibam que eu sou e não que saibam quem eu sou" (Cardano, 1932, p. 107). O que o move não é uma afirmação de si, de teor narcisista, e sim o desejo de ser. Esse desejo é esclarecido pela narrativa que ele faz no "Liber de libris propriis", no qual relata que, ainda pequeno, ao presenciar o falecimento de um jovem parente, angustiou-se pensando na brevidade da vida humana e, a partir desse momento, buscou realizar algo digno de ser lembrado para além de sua existência terrena. No meio das circunstâncias desfavoráveis de sua infância e juventude, que o tornam consciente da fragilidade de sua existência, "comecei a pensar algum modo para eu conseguir a imortalidade" (Cardano, 1932, p. 63, tradução nossa).

Coloca, em outra parte desse texto, que até a escolha dos estudos médicos foi influenciada por esse ideal: "Em minha juventude, eu me apeguei a tudo aquilo que é adequado para conservar a vida: para tanto, escolhi os estudos médicos por se parecerem mais adequados a esse mesmo fim" (Cardano, 2002, p. 113).

Cardano afirma que o efeito do "propósito de imortalizar meu nome" em suas ações é que, "durante a minha vida mortal, procurei fazer de tudo para sobreviver além do túmulo". De modo que, "mesmo se a esperança nos trai, o desejo de sobreviver é natural e louvável” (Cardano, 2002, p. 107), por 
proporcionar comportamentos adequados.

A escrita dos livros parece-lhe então um dos caminhos possíveis para realizar esse objetivo. Com efeito, como a perfeição suprema do homem é "conhecer que entende" (Cardano, 2002, p. 177), os que escrevem coisas dignas de serem lidas gozam do deleite que estas proporcionam: "Nisto consiste a autêntica durabilidade da alma: toda vez que nossos pensamentos melhores permanecem ao longo o tempo" (Cardano, 2002, p. 177). E é por esse motivo, continua, "que os sábios buscaram fazer chegar até nós, pelos seus escritos, essa parte que julgaram ser o melhor de suas próprias pessoas" (Cardano, 2002, p. 177).

$\mathrm{Na}$ parte final do "Liber de libris propriis", Cardano (2002) tece considerações sobre o fato de a escrita ser a melhor forma de conhecimentos de si mesmo:

Uma pessoa aproveita sobremaneira quando contempla a si mesma, digamos que como num espelho. Pois o espelho, mesmo que reproduza apenas a imagem do corpo, causanos, sem dúvida, grande deleite, apesar de o corpo ser apenas uma parte de nós, uma espécie de veículo, já que o homem inteiro consiste realmente em sua alma. Desse modo, portanto, quando lemos nossos escritos, nós vemos a nós mesmos como num espelho. Ajunte-se que a imagem do corpo, quando morremos, desaparece; ao passo que a imagem da alma permanece nos livros, mesmo quando o autor não está mais diante dos nossos olhos. Portanto talvez fosse melhor escrever livros do que encomendar retratos esculpidos ou pintados (p. 178).

Essa reflexão é notável por sua originalidade, numa época que ressaltava a importância do retrato (Panofsky, 1994). Cardano (2002) insiste no fato de que:

Os escritos se diferenciam dos retratos esculpidos ou pintados, por estarem à vista de todos. Além do mais, os escritos se diferenciam dos retratos, tanto quanto uma realidade imortal se diferencia de uma mortal. De fato, os escritos vão se renovando em cópias e ediçôes, as quais aumentam seu prestígio, ao passo que as imagens se perdem (p. 178).

Por fim, esse "espelho da mente", que são nossos escritos, "nos torna melhores do que somos"; ao passo que o espelho corpóreo não logra esse efeito. A durabilidade da obra escrita como sendo o melhor caminho para responder ao anseio de imortalidade é comprovada finalmente por três outros argumentos: os descobrimentos de novos fenômenos são descritos e transmitidos por textos escritos; o fato de que as verdades religiosas são preservadas e transmitidas por textos escritos; e o interesse dos príncipes em reproduzir suas gestas e ações em crônicas históricas escritas. 
Ainda em "Liber de libris propriis", Cardano (2002) afirma que, devido ao fato de "estar sempre empenhado em meus estudos e em alcançar a imortalidade", acabou se descuidando das outras coisas, de modo que "o povo, inimigo de todo bem, me criticava e condenava" (p. 66). Todavia Cardano revela ter encontrado em sua crença religiosa força para manter sua coerência com o seu ideal de vida.

\section{A consciência religiosa de Cardano}

O $22^{\circ}$ capítulo da autobiografia é dedicado à experiência religiosa do autor, da qual este declara que nunca se deixou desviar. Confessa sua entrega constante à proteção de Nossa Senhora e "do Bem-aventurado Martinho", a partir de um sonho em que lhe é revelado que deve confiar-se a esses dois padroeiros, "pois então sempre poderia conduzir uma vida calma e imortal" (Cardano, 1932, p. 164, tradução nossa).

A vivência religiosa de Cardano é um elemento que perpassa toda sua obra. Ele faz questão de reiterar com frequência que, em seus conhecimentos e em sua existência toda, "é meu desejo seguir o caminho mais seguro na fidelidade à religião em que eu nasci" (Cardano, 2002, p. 113). Essa confissão não é apenas recurso para fugir de possíveis suspeitos inquisitoriais (como se pode imaginar, com base no teor de sua obra e das vicissitudes familiares); sua sinceridade evidencia-se quando Cardano afirma ter encontrado na fé na Divina Providência a certeza positiva para enfrentar o desafio e o sofrimento de terríveis circunstâncias por que sua vida passou: "Dependemos do Destino, mais pelo significado das desgraças ocorridas que em razão de nossos próprios males" (Cardano, 2002, p. 123). A ordem misteriosa da Providência Divina que muda em bem também os males é a única certeza capaz de sustentar uma existência marcada por grandíssimas dores.

A consciência religiosa de Cardano se delineia no horizonte de sua visão desencantada do mundo a que pertence. Apesar de "muitos pensarem que nossa época é felicíssima” (Cardano, 2002, p. 173) e de que

hoje chegamos a um conhecimento completo do mundo todo, como nunca ocorrera antes; e temos tantas novidades, tantas invençōes, tantos livros, a arte da imprensa e tantas outras coisas excelentes, todavia, os homens são tão desgraçados como nunca o foram. (p. 173).

Por um lado, "os bons não podem ter seguranças"; por outro, "os maus, apesar de possuírem espadas, batalhões, dinheiro, meretrizes, jardins, fazendas e mansóes, obras de arte, cavalos e tudo o que se poderia desejar, têm, porém, 
sobre eles a certeza de que haverão de morrer" (Cardano, 2002, p. 173). E, assim, "Aquilo que para os bons seria o mais temível e pior motivo de infelicidade, é forçoso que para os maus represente o cume da felicidade: confiar (horroriza dizê-lo) que não haja nada, que não haja absoluta e eternamente nada" (Cardano, 2002, p. 173). Cardano afirma, nesse panorama, que a sabedoria baseada na fé tem-lhe proporcionado a possibilidade de vivenciar tantas injustiças e perdas sem incorrer no desespero: é essa certeza, declara, "que me permitiu chegar ao limite da condição humana" (Cardano, 2002, p. 173).

Além disso, há outra motivação que, conforme a confissão do próprio Cardano, justifica sua crença religiosa na transcendência: o fato de ele ser dotado de capacidades incomuns definidas como "estranhas à natureza" (em outro trecho, referiu-se a estas como uma "espécie de energia celeste") (Cardano, 2002, p. 174) tem evidenciado que a "Natureza me levou até os confins últimos como explorador do que existe mais além, para que, desse modo, eu o manifeste aos mortais" (Cardano, 2002, p. 174). Portanto, ao sentir-se investido de uma missão profética, Cardano afirma que seu anseio de imortalidade que perpassou o percurso todo de sua vida encontra resposta na certeza de que o que aparece não é "a meta de nossa vida, não é seu território definitivo, a não ser para aqueles que, virando as costas para a imortalidade, entregam-se aos afagos deste mundo" (Cardano, 2002, p. 173)

Essa consciência de sua missão profética insere-se, assim, numa visão crítica de seu tempo, a qual também se evidencia na última página de "De libris propriis", em que Cardano (2002) delineia sua esperança para o futuro:

Espero que, após ter descobertos tantos fatos e princípios e arcanos da natureza, importantes e úteis para a humanidade [...], apareçam homens amantes da verdade, os quais também ampliem, cultivem e aumentem até o infinito o conhecimento da natureza [...] e contribuam aos interesses da humanidade com métodos mais puros, rigorosos e complexos (p. 232).

Cardano procura compor essa visão do mundo de sabor providencialista com as teorias dos médicos e dos astrólogos, os quais atribuem os comportamentos a causas naturais inatas e aos costumes adquiridos pela educação, pelos estudos e pelas conversações. Em "Liber de libris propriiis" (Cardano, 2002), afirma ter escrito a obra "De fato" para discutir a tese de que "as coisas, muitas vezes, acontecem sem que nós mesmos as queiramos, e os acontecimentos que se entrelaçam entre si, numa ordem fixa, mostram-nos quão grande é a força do 
Destino" (Cardano, 2002, p. 65); o objetivo da obra seria exortar os leitores a viver essa condição com serenidade e abandono à Providência.

\section{A função dos sonhos e das capacidades extraordinárias segundo Cardano}

Nessa perspectiva, os sonhos também são avaliados e utilizados como sinais, ao mesmo tempo, naturais e sobrenaturais. Cardano interpreta os sonhos dentro da visão de mundo de sua época, mas, de modo um pouco anacrônico, poderíamos afirmar que sua modalidade de concepção da realidade onírica se aproxima à que Jung define como "função prospectiva" dos sonhos (Jung, 2000).

No $26^{\circ}$ capítulo da autobiografia, Cardano relata um sonho decisivo em sua vida. Trata-se de um sonho de premonição que teve acerca de sua futura esposa: a esse sonho atribui a causa de todas as suas futuras desgraças: "Aquele maldito sonho foi a porta para todas as desgraças que depois me aconteceram na vida" (Cardano, 1932, p. 181, tradução nossa).

Acerca desse mesmo sonho premonitório do casamento, na obra "Liber de libris propriis", Cardano (2002) se detém mais longamente. Relata que passou um período de vida num vilarejo chamado Sacco, sentindo-se muito desgraçado, pois desde os 20 anos, sofria por impotência sexual, até que lhe ocorreu um sonho:

Certa noite, eu sonhei que estava no Paraíso (um lugar cheio de variadas arvores frutíferas) e que me invadiu um estranho deleite. Naquele momento, enxerguei perto da porta do vestíbulo (onde eu me encontrava) uma moça vestida de branco, simplesmente trajada. Contemplei o rosto dela e me aproximei: ela permanecia fora do jardim. Logo que eu coloquei o pé fora da porta do jardim, o guarda fechou a porta. Eu me pus a pedir para entrar novamente, porém o guarda não me deixava mais entrar e me dizia: "Você estava dentro, por que resolveu sair?". Assim, eu me pus a abraçar a moça, e ela também me acariciava. Após alguns meses, quando houve o incêndio da casa de Aldobello Bandareni, que era oficial de milícias perto de Sacco, esse homem alugou uma casa próxima da minha. Ele tinha várias filhas, e a maior delas tinha o mesmíssimo aspecto e idade da moça do sonho, e usava uma roupa branca exatamente igual à figura do sonho. Eu me lembrei do sonho. [...] E me inflamei a tal ponto de amor por ela que imediatamente moveu-me a pedi-la em casamento ao pai (p. 67, tradução nossa).

Cardano confessa que, após o casamento, lançara-se numa atividade sexual desenfreada, de modo a adoecer gravemente, "Por não ter me moderado, levando em conta que convalescia de uma enfermidade recente" (Cardano, 
2002, p. 67). Relata, a seguir, que, após três abortos, a esposa pariu o filho primogênito, Gianbattista, e que, no dia do batismo, ocorreu um episódio estranho, interpretado por Cardano como presságio de desgraças: entrou pela janela da sala onde a família estava reunida com o bebê um besouro de grandes proporçôes que ficou dando voltas até bater com força no vidro da janela e cair morto. Cardano "leu" esse fato como sinal da má sorte do filho que, de fato, os acontecimentos posteriores evidenciaram. Esse foi o filho condenado à morte por uxoricídio, acusação que Cardano declara ser falsa. Cardano pensa que o filho morreu por "fatalidade e predestinação divina", sendo que, "no mesmo dia e hora em que nasceu, já estava condenado a sofrer morte semelhante" (Cardano, 1932, p. 68). Sua dor é temperada por uma visão providencialista acerca dos decretos divinos, que, como vimos, caracteriza seu pensamento. Por isso afirma ter certeza de que a Divindade restabelecerá a justiça e punirá os culpados.

No 37º capítulo, Cardano trata de alguns de seus dotes maravilhosos, entre as quais os sonhos: narra as visões tidas desde a terna infância e os sinais de premonição que o acompanham ao longo da vida inteira. Refere-se ao caráter premonitório de seus sonhos: "Neles eu lia com muita lucidez tudo o que dizia respeito às mais importantes vicissitudes de minha vida" (Cardano, 1932 , p. 277 , tradução nossa). E, para exemplificar, descreve e comenta os mais importantes sonhos de sua vida, dedicando a isso várias páginas de sua autobiografia (p. 277; 281). Na obra "Liber de libris propriis", Cardano (2002) também se refere amplamente aos seus sonhos em vários pontos do texto.

Cardano também destaca ter capacidades extraordinárias, a cuja ilustração dedica o $38^{\circ}$ capítulo da autobiografia. São elas: a audição de vozes; a visão do futuro próximo pelos sonhos; o resplendor, ou seja, uma luz emanada por volta dele em algumas circunstâncias; a capacidade de conservar a vida em situações extremas e diante das mudanças repentinas da fortuna sofridas em vários momentos de sua história. Outros capítulos também são dedicados ao relato das manifestações naturais e singulares de sua vida. Cardano (1932, p. 349) comenta a utilidade de suas capacidades de presságio para as artes médicas, coloca serem elas um "dom divino ou natural e não fruto de um ânimo aterrorizado ou de algum modo comovido, ou agitado".

Cardano atribui esse dom divino a um espírito que se faz presente nele e a esse "meu espírito" dedica o $47^{\circ}$ capítulo. Declara-se convencido de que é "um espírito bom e misericordioso e não um espírito demoníaco" (Cardano, 1932, p. 390). Diz-se persuadido de que, já há algum tempo, o dito "espírito" mora nele, mas que somente na ocasião do aniversário, aos 74 anos de idade, quando começou a escrever os acontecimentos de sua vida, compreendeu 
como esse espírito lhe manifestava os fatos que estavam para acontecer. Nesse sentido, a escrita autobiográfica teve uma função reveladora para a plena compreensão do "si mesmo", incluindo-se os aspetos fora da normalidade. Afirma: "Tantas coisas iminentes e que estavam para acontecer revelaram-se para mim de uma forma tão clara que parecia quase um prodígio que isso ocorresse sem a intervenção divina" (Cardano, 1932, p. 391); de modo que somente a admissão da existência de um "espírito" sobrenatural agindo nele explicaria o fenômeno. Ao indagar o motivo pelo qual Deus o agraciou com tão grandes dons, responde: "Pode ser que seja pelo imenso amor que tenho pela verdade e pela sabedoria", e pela indiferença diante dos bens materiais, como também "pelo meu desejo de justiça" ou "pelo motivo de eu tudo atribuir a Deus e nada a mim mesmo", "ou talvez por algum outro motivo que só Ele sabe” (Cardano, 1932, p. 392).

\section{Conclusão}

No $46^{\circ}$ capítulo, conclusivo da autobiografia, cujo título é "Acerca de mim mesmo", elabora uma síntese de sua longa história. Inicia com uma referência ao leitor: "A ti, leitor, que meditas acerca de minhas vicissitudes, eu compreendo vir espontânea a pergunta: ou seja, se levando em conta tudo o que me ocorreu, todos os casos, tristes, alegres e indiferentes, desagrade-me o viver ou o ter vivido" (Cardano, 1932, p. 385, tradução nossa). E responde que, apesar das inumeráveis desgraças vivenciadas, ao comparar-se a outros desgraçados, não teria direito de queixar-se, pois, de qualquer forma, recebeu o dom de muitas "cognições" e de "grandes, seguras e raras qualidades". Devido a isso, afirma ter conseguido desprezar as coisas mortais, assim como o fizeram os estoicos, e acredita ser "muito feliz por saber que nossa natureza participa da Divindade", sendo que "Deus quis no tornar partícipes a nós mortais de sua vida imortal" (Cardano, 1932, p. 387). Por fim, no epílogo de sua longa e pormenorizada narrativa autobiográfica, Cardano declara que, apesar de que possivelmente nem todos os leitores compreenderão sua confissão, "nada me guiou nas minhas narrativas a não ser o amor pela verdade" (Cardano, 1932, p. 461).

Desse modo, encerra esse longo percurso em que a escrita de si the proporciona o balanço de sua dramática história de vida e, sobretudo, o entendimento da complexidade de sua personalidade. Complexidade de um sujeito particular, mas também de um homem de seu tempo, no qual convivem aspetos antinômicos: a visão religiosa do mundo e o fascínio pelas capacidades humanas (ordinárias e extraordinárias) de dominá-lo, a 
percepção da contingência e a busca da permanência, a afirmação de Deus e a afirmação de si mesmo. A unidade desse mosaico multifacetado é tematizada por Cardano pela identificação de uma espécie de linha condutora de sua história pessoal, a qual definimos como experiência elementar: o anseio pela transcendência, pela imortalidade que, em sua ótica, confere significado a todos os seus posicionamentos e açóes ao longo do tempo. O conhecimento de si pela escrita não se restringe, assim, a uma simples descrição e encadeamento de fatos da história biográfica e de características pessoais, mas oferece aos leitores uma interpretação de si mesmo à luz da identificação de suas motivações fundamentais.

\section{Referências}

Battistini, A. (2000). Il barocco. Roma: Salerno.

Canziani, G. (2009). L'immortalité de l'âme chez Cardan entre histoire naturelle et vision de Dieu. In J. Y. Boriaud (Eds.), La pensée scientifique de Cardan. (pp. 131-146). Paris: Les Belles Lettres.

Cardano, G. (1932). Autobiografia. (B. Angelo, Trad.). Milano: La Famiglia Meneghina Editrice.(Biblioteca Ambrosiana, A.S. 3599). [Trabalho original de 1576].

Cardano, G. (2002). Mis libros. (S. Francisco, Trad., Org.). Madri: Akal. [Trabalho original de 1562].

Jung, C. G. (2000). A natureza da psique. (R. R. Mateus, Trad.). Petrópolis: Vozes. [Trabalho original de 1971].

Mahfoud, M. (2012). Experiência elementar em Psicologia: aprendendo a reconhecer. Belo Horizonte: Universa.

Marco Aurélio. (2001). Colloqui con sé stesso. (T. Enrico, Trad.). Milano: Fabbri Editori. [Trabalho original de 179 d.C.[.

Massimi, M. (2005). Palavras, almas e corpos no Brasil colonial. São Paulo: Editora Loyola.

Massimi, M. (2011). A fonte autobiográfica como recurso para a apreensão do processo de elaboração da experiência na história dos saberes psicológicos. 
Memorandum, 20, 11-30. Recuperado a partir de http://www.fafich.ufmg. $\mathrm{br} / \mathrm{memorandum} / \mathrm{a} 20 / \mathrm{massimi05}$.

Míssio, E. (2005). A dissimulação como virtude entre os jesuítas da ContraReforma. Memorandum, 9, 121-131. Recuperado a partir de http://www. fafich.ufmg.br/ - memorandum/a09/missio01.htm.

Panofsky, E. (1994). Idea: a evolução do conceito de belo. (P. Neves, Trad.). São Paulo: Martins Fontes.

Watson, R. I. (1998). Abordagem sociopsicológica: o estudo da personalidade. In J. Brožek \& M. Massimi. Historiografia da Psicologia moderna: versão brasileira. (J. A. Ceschin \& J. C. S. Paulo, Trad.) (pp. 389-398). São Paulo: Unimarco, Loyola. 